\title{
Penguatan Kompetensi Pedagogik Guru melalui Penggunaan Dynamic Geometry Software dalam Pembelajaran Matematika
}

\author{
Silfanus Jelatu ${ }^{1}$, Ricardus Jundu ${ }^{2}$, Emilianus Jehadus ${ }^{2}$, Fransiskus Nendi ${ }^{2}$, \\ Alberta Parinters Makur², Gabariela Purnama Ningsi², Lana Sugiarti ${ }^{2}$ \\ 1, 2 Universitas Katolik Indonesia Santu Paulus Ruteng, Indonesia
}

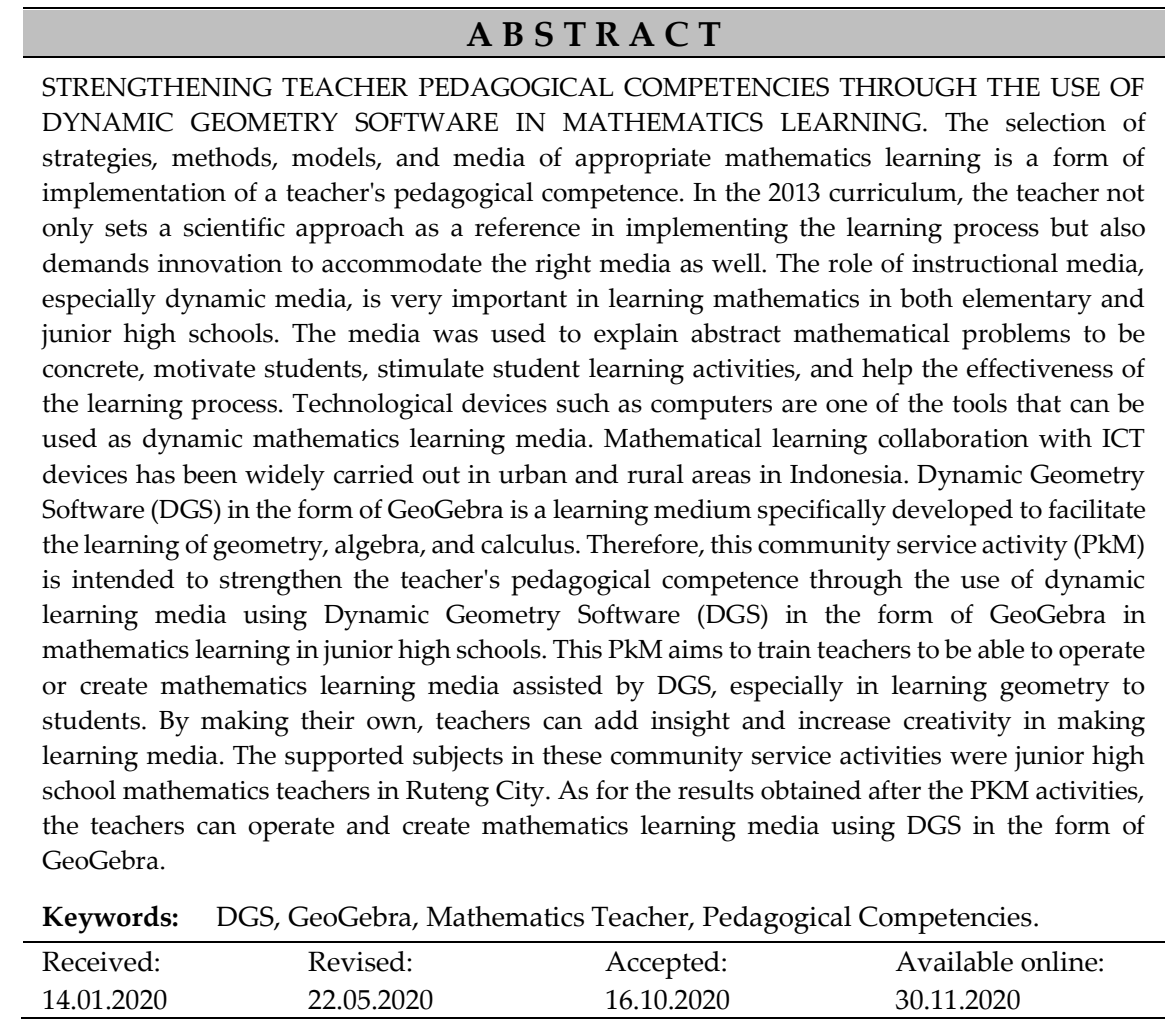

\section{Suggested citation:}

Jelatu, S., Jundu, R., Jehadus, E., Nendi, F., Makur, A. P., Ningsi, G. P., \& Sugiarti, L. (2020). Penguatan kompetensi pedagogik guru melalui penggunaan dynamic geometry software dalam pembelajaran matematika. Jurnal Pengabdian Pada Masyarakat, 5(4), 1025-1034. https://doi.org/10.30653/002.202054.400

Open Access I URL: http://ppm.ejournal.id/index.php/pengabdian/article/view/400

${ }_{1}^{1}$ Corresponding Author: Program Studi Pendidikan Matematika, FKIP Universitas Katolik Indonesia Santu Paulus Ruteng; Jl. A. Yani No. 10, Ruteng, Flores, NTT, Indonesia. Email: silfanusjelatu@yahoo.co.id 


\section{PENDAHULUAN}

Studi tentang peningkatan hasil belajar matematika siswa tak dapat dipisahkan dari pembicaraan tentang kualitas tenaga pengajar. Namun, dalam beberapa tahun terakhir, studi yang dilakukan oleh OECD menyimpulkan bahwa merekrut dan mempertahankan guru yang berkualitas telah menjadi tantangan di antara beberapa negara (OECD, 2019). Kualitas guru merupakan faktor penting dalam menentukan perolehan prestasi siswa, selain setelah memperhitungkan hasil pembelajaran siswa sebelumnya dan karakteristik latar belakang keluarga. Beberapa prediktor kualitas guru biasanya memasukkan faktor-faktor seperti sertifikasi, kualifikasi, gelar yang diperoleh, atau pengalaman mengajar. Namun, salah satu aspek atau indikator lain yang memperkuat kualitas guru pada umumnya yang juga mencakup guru matematika adalah pengetahuan atau kompetensi pedagogis guru. Pengetahuan pedagogis mengacu pada pengetahuan khusus guru untuk menciptakan lingkungan belajar dan mengajar yang efektif untuk semua siswa.

Shulman (1986) menjelaskan bahwa kompetensi pedagogik adalah sejenis pengetahuan khusus sebagai pengetahuan dasar bagi guru yang mencakup koneksi berbagai pengetahuan dan keterampilan representasi, analogi, contoh, demonstrasi suatu materi agar dapat dipahami oleh siswa. Pengetahuan pedagogis akan berkontribusi terhadap konsistensi antara apa yang direncanakan dan apa yang dipraktikkan dalam proses belajar mengajar matematika di sekolah (Muhtarom, Juniati, \& Siswono, 2019). Pemahaman pedagogis yang baik serta pengetahuan matematika bisa mempengaruhi proses pembelajaran di kelas secara positif. Selain menguasai konten matematika yang diajarkan, guru juga harus tahu cara mentransfer pelajaran sehingga siswa dapat memahaminya dengan mudah. Namun, menurut Ma'rufi, Budayasa and Juniati (2018), pengetahuan tentang konten dan pengetahuan pedagogik tidak cukup untuk mendapatkan praktik mengajar yang efektif tanpa pengetahuan siswa, kurikulum, tujuan pendidikan, dan bahan ajar.

Kompenetsi pedagogis guru dapat ditunjukan melalui kegiatan perencanaan pembelajaran, dimana guru merancang tentang pola eksperimen serta pengalamanpengalaman belajar yang efektif untuk siswa. Guru yang efektif merencanakan pengalaman belajar matematika akan memungkinkan siswa untuk mengembangkan keahlian, minat, serta atensi. Rekomendasi penelitian terkini menuliskan bahwa dalam merencanakan pembelajaran, guru secara efektif menempatkan pengetahuan dan minat siswa di dalam keputusan perencanaan instruksional yang dibuat. Untuk membangun keahlian, guru menyesuaikan instruksi yang dibuat untuk untuk memenuhi kebutuhan belajar siswa. Hal ini sejalan dengan pandangan teori belajar modern yang memandang berpikir sebagai "pemahaman yang sedang berjalan", guru dapat menggunakan pemikiran siswa sebagai sumber untuk pembelajaran lebih lanjut (Anthony \& Walshaw, 2009). Guru-guru seperti itu responsif terhadap siswa mereka dan terhadap disiplin matematika.

Berkaitan dengan perencanaan pembelajaran, Pemerintah RI melalui Kementerian Pendidikan dan Kebudayaan telah mengatur tentang pembelajaran kolaboratif dengan melibatkan perangkat teknologi. Salah satu inovasi yang dapat dibuat oleh guru dengan beragam cara yaitu membuat skenario pembelajaran yang menyenangkan serta memanfaatkan media pembelajaran. Guru harus dapat menumbuhkan kesadaran 
siswa dalam melakukan aktivitas pembelajaran sehingga siswa tidak hanya memiliki keterampilan melakukan sesuatu tetapi harus memahami mengapa aktivitas itu dilakukan dan apa implikasinya (Hajer \& Norén, 2017). Banyak media pembelajaran yang bisa digunakan oleh guru, dengan memanfaatkan lingkungan sekitar ataupun berkreasi sendiri. Kreasi media pembelajaran yang dibuat guru dapat bermacam bentuk, salah satu yang dapat dibuat adalah media pembelajaran menggunakan komputer.

Media pembelajaran menggunakan komputer dapat menjadi alternatif pilihan yang digunakan guru dalam proses belajar mengajar. Media pembelajaran berbasis komputer mempunyai banyak kelebihan diantaranya bisa memberikan efek visual, animasi, dan suara yang menarik serta dinamis. Dengan tampilan visual yang menarik siswa akan lebih senang dan tertarik untuk mempelajari kompetensi yang disajikan (Chipangura \& Aldridge, 2019; Yulianti, Buchori, \& Murtianto, 2017). Saat ini, salah satu media pembelajaran matematika berbasis komputer yang cukup familiar adalah aplikasi Dinamic Geometry Software (DGS).

Untuk konsep yang berkaitan dengan geometri dan pengukuran, Dynamic Geometry Software (DGS) adalah alat yang efektif dan fleksibel untuk matematikawan, seperti teleskop atau mikroskop bagi para ilmuwan, untuk membuat penemuan baru dan menguji teorema (Oldknow dalam Özçakir and ÇakiroĞlu, 2019). DGS dapat menyediakan lingkungan belajar yang sangat berharga untuk geometri sekolah (Doğan \& Içel, 2011; Karakuş \& Peker, 2015). Lebih lanjut Özçakir and ÇakiroĞlu (2019) menerangkan bahwa karakteristik DGS yang paling penting bagi lingkungan tradisional adalah bahwa objek, yang digambar atau dibangun, dapat dipindahkan dan diubah ukurannya secara interaktif. Dengan kata lain, siswa dapat memanipulasi bentuk geometris dan dapat mengamati perubahan dengan pengukuran waktu yang nyata dengan DGS.

GeoGebra, dikembangkan oleh Markus Hohenwarter, adalah contoh DGS, dan digunakan sebagai alat pembelajaran yang banyak digunakan dalam pembelajaran geometri di sekolah. DGS berupa GeoGebra merupakan salah satu aplikasi yang dapat diinstal dalam berbagai komputer. Aplikasi ini dikembangkan secara khusus untuk memfasilitasi visualiasi konsep-konsep geometri secara dinamis (Jelatu, Sariyasa, \& Ardana, 2018; Martín-Caraballo \& Tenorio-Villalón, 2015; Sari, Farida, \& Syazali, 2016). Kemudahan aplikasi ini adalah tersedianya bahasa Indonesia dalam semua fiturfiturnya, serta dapat diunduh secara gratis. DGS berupa GeoGebra dapat membantu guru saat mengajar geometri dua dimensi dan tiga dimensi ((Hohenwarter, Hohenwarter, Kreis, \& Lavicza, 2008)). Beberapa peneliti telah menunjukan efek pembelajaran berbasis komputer dengan DGS berupa GeoGebra. Mereka menemukan bahwa penggunaan GeoGebra sebagai media pembelajaran matematika bermanfaat untuk pembelajaran siswa dan dapat mengembangkan pemahaman mereka dalam geometri karena siswa dapat mengeksplorasi, menduga, membangun, dan mendefinisikan hubungan geometris saat berinteraksi dengan GeoGebra ((Bulut, Akçakın, Kaya, \& Akçakın, 2016; Jelatu et al., 2018; Tatar, 2012; Zulnaidi \& Zakaria, 2012)). Secara keseluruhan, hasil penelitian tersebut menemukan bahwa siswa dalam kelompok yang didukung DGS berkinerja lebih baik daripada siswa dalam kelompok yang didukung manipulatif fisik. 
Di Indonesia, aplikasi ini hampir telah digunakan oleh banyak guru-guru. Namun, berdasarkan hasil observasi serta wawancara dengan beberapa guru di kabuaten Manggarai dan Manggarai Timur, NTT, penulis memperoleh informasi bahwa penggunaan media berbasis ICT seperti DGS GeoGebra belum diaplikasikan dalam pembelajaran matematika. Salah satu penyebabnya adalah adanya kesulitan dalam mengoperasikan GeoGebra. Beberapa guru di beberapa sekolah mengeluhkan tentang ketiadaan fasilitas dasar seperti listrik. Namun, untuk sekolah di daerah perkotaan yang juga dilengkapi dengan fasilitas mengungkapkan bahwa sebagian besar belum mampu mengoperasikan media ICT atau software pembelajaran matematika.vOleh karena itu, penulis berinisiatif untuk melakukan pelatihan tentang pembuatan media interaktif menggunakan DGS berupa GeoGebra sebagai upaya penguatan kompetensi pedagogik guru.

\section{METODE}

Tahapan kegiatan pengabdian masyarakat ini dibagi menjadi 3 tahapan, yaitu: Pertama, Persiapan. Pada tahap persiapan dilakukan observasi terhadap media pembelajaran yang digunakan guru di sekolah. Observasi dilakukan untuk mengetahui media pembelajaran apa saja yang sering digunakan guru dalam mengajar. Setelah diketahui masalahnya maka disusun suatu solusi untuk diterapkan dalam tahap pelaksanaan. Selain itu, pada kegiatan persiapan juga dilakukan kegiatan-kegiatan yang meliputi diskusi program kegiatan PkM dengan guru-guru tentang masalah yang mereka hadapi khususnya dalam proses pembuatan media pembelajaran dan menjelaskan program PkM yang akan dilakukan. Selanjutnya melakukan penyusunan program pelatihan. Kedua, Pelaksanaan. Proses pelaksanaan terbagi menjadi 2, yaitu: (1) Sosialisasi. Tahap ini bertujuan untuk memberikan pengetahuan kepada guru-guru matematika bahwa terdapat teknologi yang dapat digunakan oleh guru untuk membuat media pembelajaran animasi. Teknologi tersebut ialah Dynamic Geometry Software berupa GeoGebra. (2) Pelatihan. Pelatihan pengembangan media pembelajaran animasi berbasis komputer menggunakan Dynamic Geometry Software berupa GeoGebra akan dilakukan praktik secara langsung. Masing-masing peserta akan memegang satu komputer dan langsung mempraktekkan apa yang dijelaskan oleh instruktur. Dan (3) Observasi. Observasi dilakukan selama proses pelatihan berlangsung. Instrumen yang digunakan berupa catatan lapangan. Beberapa hal yang diobservasi adalah kendalakendala, kekurangan-kekurangan, dan kelemahan-kelemahan yang muncul selama proses pelatihan. Ketiga, Evaluasi. Evaluasi dilakukan terhadap kuantitas dan kualitas media yang dihasilkan oleh guru-guru.

\section{HASIL DAN PEMBAHASAN}

Tahap pertama yang dilakukan dalam kegiatan ini adalah observasi, diskusi solusi dan persiapan. Adapun dasar pelaksanaan observasi, keputusan solusi, dan persiapan kegiatan PkM ini diuraikan oleh tim sebagai berikut:

Rekomendasi kurikulum dan tuntutan ketercapaian proses pembelajaran yang relevan dengan kondisi dunia merupakan landasan penulis dalam memproyeksi 
kegiatan PkM ini. Kurikulum Tingkat Satuan Pedidikan (KTSP) yang disempurnakan dalam kurikulum 2013 mengharuskan adanya pembelajaran interaktif yang memfasilitasi pengembangan proses "berpikir" peserta didik. Dunia di era pengetahuan dan teknologi saat ini menginginkan manusia yang "selalu berpikir ", berpengetahuan, dan melek teknologi.

Salah satu scope pembicaraan yang relevan dengan kesanggupan dalam menjalankan kehidupan di era digital adalah pendidikan yang direfleksikan melalui proses pembelajaran. Pembelajaran matematika merupakan salah satu bagian penting dalam dunia pendidikan mengingat matematika merupakan ilmu yang menjembatani perkembangan dunia dan ilmu pengetahuan. Oleh karena itu, proses pembelajaran matematika pun harus benar-benar mengakomodasi kegiatan berpikir.

Lingkungan belajar yang baik tentu akan menciptakan proses pembelajaran matematika yang baik pula. Pada bagian ini, kompetensi pedagogik seorang guru matematika yang lebih dominan dimunculkan. Pemilihan strategi, pendekatan, metode, model, dan media pembelajaran matematika serta melakukan proses penilaian secara benar merupakan domain dari kompetensi pedagogik.

Dalam kurikulum 2013, secara khusus ditekankan terkait penggunaan media pembelajaran matematika yang interaktif. Lebih khusus lagi ditekankan penggunaan media pembelajaran matematika interaktif berbasis ICT seperti penggunaan komputer, smartphone, dan lain-lain. Sebagian besar sekolah di Indonesia telah dengan efektif menerapkan pembelajaran matematika berbantuan media berbasis ICT. Namun, beberapa daerah juga belum sepenuhnya menerapkan media pembelajaran ICT oleh karena alasan yang bervariasi diantaranya, fasilitas yang belum memadai, kemampuan mengoperasikan perangkat teknologi berupa apllikasi pembelajaran yang kurang dan bahkan tidak bisa, serta anggapan bahwa penggunaan proses pembelajaran tradisional masih bagus.

Hasil observasi penulis di beberapa sekolah menengah pertama di kabupaten Manggarai, NTT, menunjukan bahwa penggunaan media pembelajaran berbasis ICT belum dilakukan. Beberapa guru di beberapa sekolah mengeluhkan tentang ketiadaan fasilitas dasar seperti listrik. Namun, untuk sekolah di daerah perkotaan yang dilengkapi dengan fasilitas pendukung mengungkapkan bahwa sebagian besar belum mampu mengoperasikan media ICT atau software pembelajaran matematika. Setelah mendapatkan informasi ini, maka tim PkM menyusun suatu solusi berupa kegiatan PkM mengenai penggunaan media pembelajaran matetika interaktif berbantuan Dynamic Geometry Software berupa aplikasi GeoGebra.

Setelah tim PKM dan para guru menyepakati untuk mengadakan kegiatan ini, tim PKM melakukan diskusi untuk mempersiapkan bahan atau materi-materi pelatihan, jadwal serta tugas-tugas anggota tim saat kegiatan. Kesepakatan pertama yang dihasilkan ialah menetapkan satu orang untuk menjadi moderator, dua orang pemateri, sedangkan anggota lainnya sebagai pendamping peserta. Materi-materi yang diberikan ialah materi tentang pentingnya penggunaan media pembelajaran berbasis ICT dalam pembelajaran matematika dan materi tentang cara menggunakan aplikasi. Sedangkan pendampingan dilakukan saat proses penginstalan dan pengoperasian aplikasi.

Pada tahap pelaksanan, kegiatan diawali dengan pemberian materi I dengan tema "Pembelajaran Matematika Kekinian: Integrasi Media Interactif berbasis ICT". Kegiatan 
ini sangat interaktif, dimana peserta banyak mengajukan pertanyaan dan dijawab atau diterangkan dengan baik pula oleh pemateri. Beberapa peserta mengaku sangat senang dan memperoleh pengatahuan baru baik dari segi pengembangan kompetensi pedagogik maupaun tentang gambaran pembelajaran matematika yang diinginkan atau relevan dengan era saat ini.

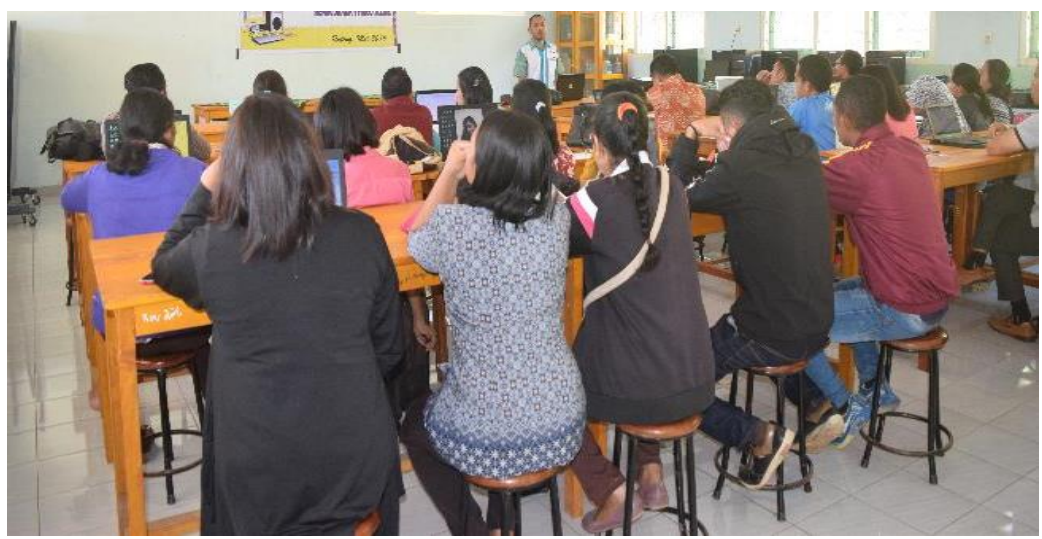

Gambar 1. Para peserta saat menyimak materi I

Selanjutnya pada materi II tentang penggunaan atau mendesain media pembelajara matematika berbantuan GeoGebra, pemateri menjelaskan tentang cara mendownload, menginstal dan menggunakan aplikasi GeoGebra. Di saat bersamaan, angota tim yang lain mendampingi peserta kegiatan.

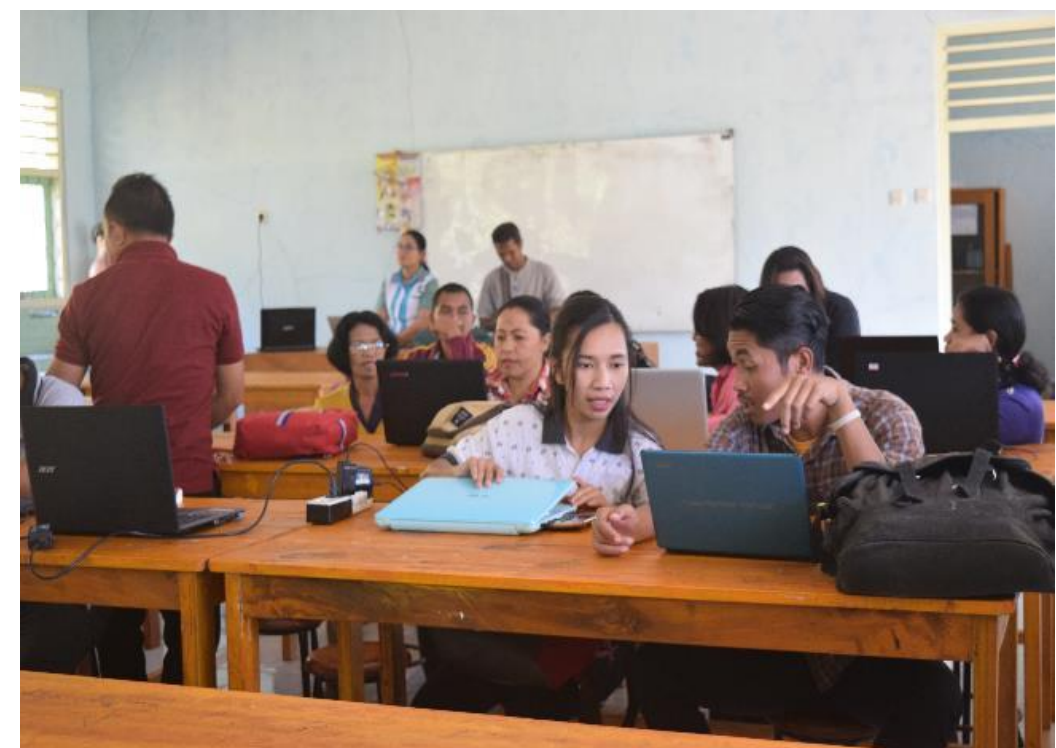

Gambar 2. Peserta dan pendamping Mengoperasikan GeoGebra

Pada saat mendownload aplikasi, banyak peserta mengalami kesulitan karena tidak terkoneksi jaringan internet. Namun, pemateri dan pendamping memberikan modul cara mendowload dan menyerahkan aplikasi yang sudah didownload untuk diinstal. Alasan peneliti menunjukan cara mendwnload ialah agar peserta melihat secara langsung bahwa aplikasi GeoGebra tersedia secara gratis di internet. 


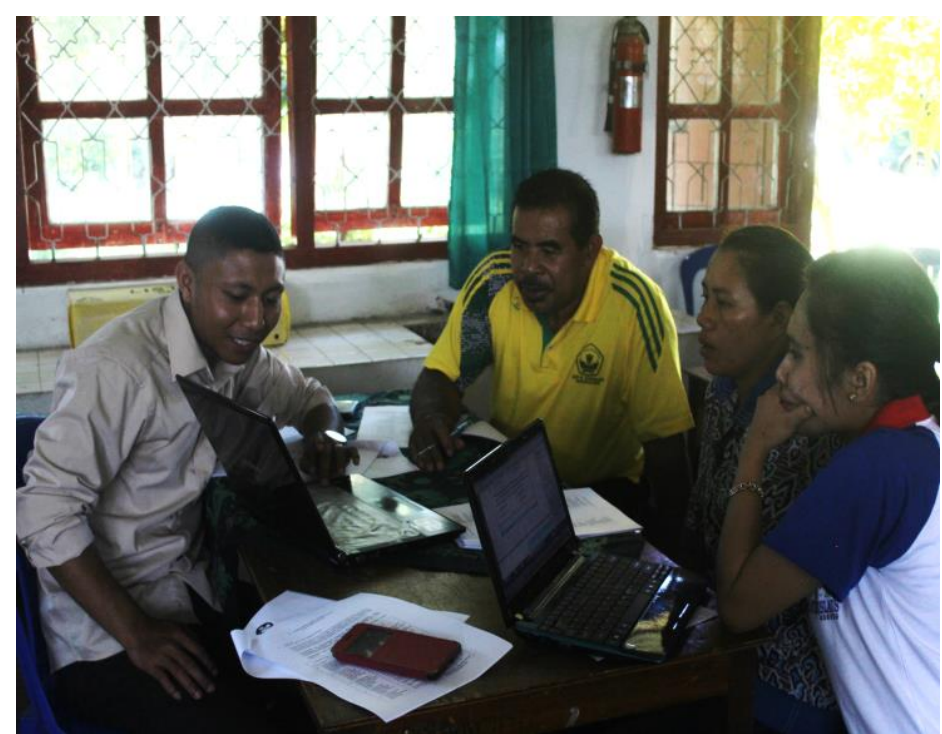

Gambar 3. Pendamping bersama peserta

Pada saat melakukan observasi, tim PKM melihat bahwa peserta sangat aktif dan interaktif selama kegiatan. Sirkulasi pertanyaan dan jawaban selama audiensi dan pendampingan menjadi dasar kesimpulan tentang peserta yang aktif dan interaktif. Selaian itu, peserta memiliki kesan positif terhadap dampak kegiatan ini. Namun, ada juga peserta yang merasa kesulitan dalam mengoperasikan komputer. Mereka adalah guru-guru yang usia pengabdiannya sudah lama.

Ukuran ketercapaian dari kegiatan ini dinilai melalui proses evaluasi. Hasil berupa kualitas dan kuantitas merupakan dasar dari proses penialaian. Pada aspek kualitas, beberapa peserta dapat mencipatakan produk berupa file hasil pengembangan yang memuat animasi-animasi, dan bentuk kreasi. Pada aspek kuantitas, hampir semua peserta membuat produk sederhana berbasis DGS sejumlah dua produk pada setiap materi geometri yang dipilih. Salah satu hasil pengembangan peserta dapat di lihat pada gambar berikut:

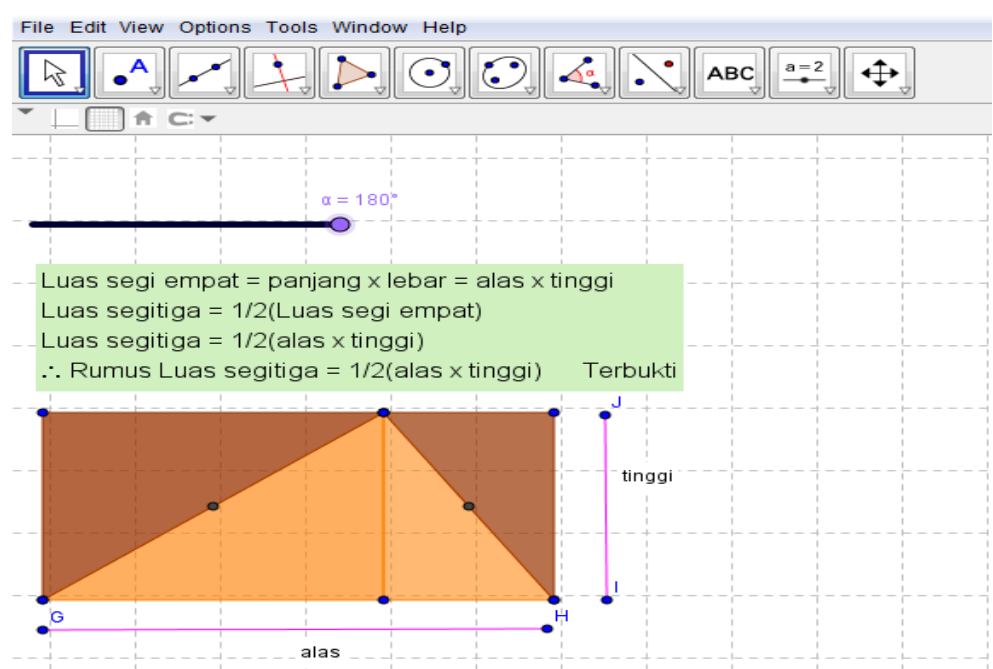

Gambar 4. Hasil Pengembangan Peserta 
Pada Gambar 5, peserta mendesain visualiasi pembuktian rumus luas segitiga yang diperoleh dari rumus persegi panjang. Ekperimentasi dilakukan dengan cara menggerakan slider agar bagian-bagain persegi yang dibatasi oleh garis-garis bergerak secara dinamis menjadi segitiga. Dengan demikian eksplorasi tentang rumus segitiga dapat divisualisasikan.

\section{SIMPULAN}

Dari uraian-uraian di atas serta merujuk pada hasil observasi lagsung, penulis berkesimpulan bahwa sebagian besar peserta dapat mengoperasikan media GeoGebra untuk memvisualisaikan konsep matematika secara sederhana. Sedangkan ada beberapa guru yang sudah bias memanaatkan fitur-fitur animasi dan fitur dinamis lainnya dengan baik. Berdasarkan hasil pengamatan saat observasi serta produk yang dihasilkan, tim PKM berkesimpulan bahwa kegiatan PKM ini berjalan dengan lancar.

Hampir semua peserta mengaku akan mengakomodasi media DGS berupa GeoGebra dalam proses pembelajaran matematika khususnya geometry di SMP. Gambaran ini menunjukan bahwa kegiatan PkM ini berdampak positif pada penguatan kompetensi pedagogik guru berupa pemanfaatan media pembelajaran dinamis berupa $D G S$. Selain itu, informasi tambahan yang diperoleh langsung dari peserta bahwa mereka akan melakukan pengembangan lebih banyak lagi untuk setiap topik pada pembelajaran geometri.

Selanjutnya, dari kegiatan pelatihan ini, tim PKM menyarankan kepada peserta agar peserta dapat mengaplikasikan media GeoGebra untuk materi matematika yang lain (yang masih memungkinkan untuk disampaikan dengan menggunakan GeoGebra). Selain itu, peserta harus selalu berinovasi untuk mmencipatakan pembelajaran yang berorientasi pada proses berpikir siswa terhadap suatu materi dan memberikan pengalaman belajar yang baru bagi siswa.

\section{Ucapan Terima Kasih}

Terima kasih kepada Yayasan Santu Paulus Ruteng melalui LPPM Universitas Katolik Indonesia Santu Paulus yang telah membiayai seluruh kegiatan PKM ini. Terima kasih pula kepada Kepala SMP Negeri 5 Ruteng yang telah mengijinkan tempat dan fasilitas untuk mendukung pelaksanaan kegiatan PKM ini.

\section{REFERENSI}

Anthony, G., \& Walshaw, M. (2009). Effective pedagogy in mathematics. France: International Academy of Education.

Bulut, M., Akçakın, H. Ü., Kaya, G., \& Akçakın, V. (2016). The effects of geogebra on third grade primary students' academic achievement in fractions. Mathematics Education, 11(2), 327-335. https://doi.org/10.12973/iser.2016.2109a 
Chipangura, A., \& Aldridge, J. (2019). Multimedia : A Means of Improving Students ' Engagement in Mathematics Classrooms? International Journal For Mathematics Teaching And Learning, 20(2), 193-211.

Doğan, M., \& Içel, R. (2011). The role of dynamic geometry software in the process of learning: GeoGebra example about triangles. International Journal of Human Sciences, $8(1), 1441-1458$.

Hajer, M., \& Norén, E. (2017). Teachers ' Knowledge about Language in Mathematics Professional Development Courses : From an Intended Curriculum to a Curriculum in Action. EURASIA Journal of Mathematics Science and Technology Education, 13(17b), 4087-4114. https://doi.org/10.12973/eurasia.2017.00808a

Hohenwarter, M., Hohenwarter, J., Kreis, Y., \& Lavicza, Z. (2008). Teaching and Learning Calculus with Free Dynamic Ma- thematics Software GeoGebra Calculus with GeoGebra. Proceedings of the International Conference on the Teaching of Mathematics - TSG 16, 1-9.

Jelatu, S., Sariyasa, S., \& Ardana, I. M. (2018). Effect of GeoGebra-Aided REACT Strategy on Understanding of Geometry Concepts. International Journal of Instruction, 11(4), 325-336. https://doi.org/10.12973/iji.2018.11421a

Karakuş, F., \& Peker, M. (2015). The Effects of Dynamic Geometry Software and Physical Manipulatives on Pre- Service Primary Teachers' Van Hiele Levels and Spatial Abilities. Turkish Journal of Komputer and Mathematics Education, 6(3), 338-365. https://doi.org/10.16949/turcomat.31338

Ma'rufi, Budayasa, I. K., \& Juniati, D. (2018). Pedagogikal Content Knowledge: Teacher's Knowledge of Students in Learning Mathematics on Limit of Function Subject. Journal of Physics: Conference Series 954(1), 1-8. https://doi.org/10.1088/1742$6596 / 954 / 1 / 012002$

Martín-Caraballo, A. M., \& Tenorio-Villalón, Á. F. (2015). Teaching numerical methods for non-linear equations with Geogebra-based activities. International Electronic Journal of Mathematics Education, 10(2), 53-65.

Muhtarom, Juniati, D., \& Siswono, T. Y. E. (2019). Examining Prospective Teachers' Belief and Pedagogikal Content Knowledge Towards Teaching Practice in Mathematics Class: A Case Study. Journal on Mathematics Education, 10(2), 185-202.

OECD. (2019). Teachers 'Pedagogikal Knowledge and the Teaching Profession. Paris: OECD Publishing.

Özçakir, B., \& ÇakiroĞlu, E. (2019). Effects of Dynamic Geometry Activities on Seventh Graders ' Learning on Area of Quadrilaterals. International Journal For Mathematics Teaching And Learning, 20(2), 257-271.

Sari, F. K., Farida, \& Syazali, M. (2016). Pengembangan Media Pembelajaran (Modul) berbantuan Geogebra Pokok Bahasan Turunan. Al-Jabar: Jurnal Pendidikan Matematika, 7(2), 135-152. 
Shulman, L. S. (1986). Those Who Understand: Knowledge Growth in Teaching. Educational Researcher, 15(2), 4-14.

Tatar, E. (2012). The effect of dynamic mathematics software on achievement in mathematics: The case of trigonometry. Energy Education Science and Technology Part B: Social and Educational Studies, 4(1), 459-468. https://doi.org/10.1016/j.sbspro.2011.12.038

Yulianti, Buchori, A., \& Murtianto, Y. H. (2017). Pengembangan Media Presentasi Visual dengan Pendekatan Kontekstual dalam Pembelajaran Matematika di SMP. MUST: Journal of Mathematics Education, Science and Technology, 2(2), 231-242.

Zulnaidi, H., \& Zakaria, E. (2012). The Effect of Using GeoGebra on Conceptual and Procedural Knowledge of High School Mathematics Students. Asian Social Science, 8(11), 102-106. https://doi.org/10.5539/ass.v8n11p102

\section{Copyright and License}

This is an open access article distributed under the terms of the Creative Commons Attribution 4.0 International License, which permits unrestricted use, distribution, and reproduction in any medium, provided the original work is properly cited.

(C) 2020 Silfanus Jelatu, Ricardus Jundu, Emilianus Jehadus, Fransiskus Nendi, Alberta Parinters Makur, Gabariela Purnama Ningsi, Lana Sugiarti. 